\title{
Safety assessment of strengthened floor slab structures in a historic department store in Wroclaw
}

\author{
Leopold Kruszka ${ }^{1, *}$ \\ ${ }^{1}$ Faculty of Civil Engineering and Geodesy, Military University of Technology, \\ 2 Urbanowicza St., 00-908 Warsaw, Poland
}

\begin{abstract}
The subject of the paper are existing intermediate steel/ceramic ceiling structures on four levels from "-1" to "2" in a remodelled historic department store in Wroclaw, which are reinforced with an extra concrete flooring slab cast on a trapezoidal sheet in the post-war period. The purpose of this work is to check the possibility of leaving in these reinforced brick slabs with Förster's clay block, ceiling structures, as part of the reconstruction of this building after 2005. The scope of work includes the diagnostics of structural elements for these floor slabs with material tests.
\end{abstract}

\section{Introduction}

The monumental, seven-storey building of Renoma" department house, formerly called "Wertheim", was built in 1930 (Fig. 1a). At the end of The Second World War, on March 12, 1945, it was bombed and was being engulfed in flames for several days (Fig. 1b). It was reopened after three years in 1948, during the Regained Territories Exhibition as the largest Department Store in Poland - Fig. 2a.

a)

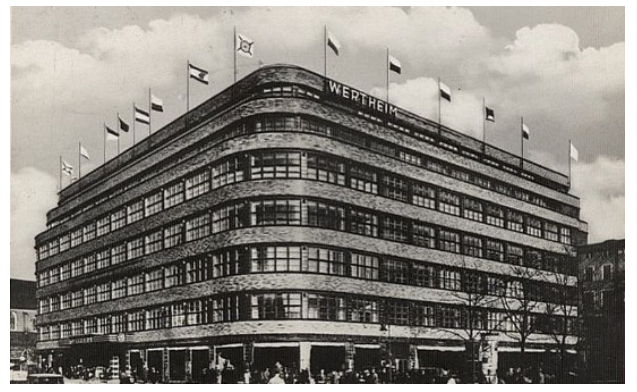

b)

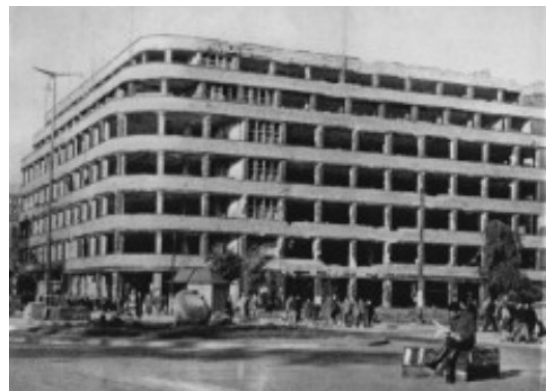

Fig. 1. a) The building of the pre-war "Wertheim" department store - 1932-1934 [source: Public domain: https://polska-org.pl/612875,foto.html], b) Burnt department store after the Second World War [source: Public domain: https://polska-org.pl/photo/file.action?thumbFit300x180=\&id=930818].

\footnotetext{
*Corresponding author: leopold.kruszka@wat.edu.pl
} 
a)

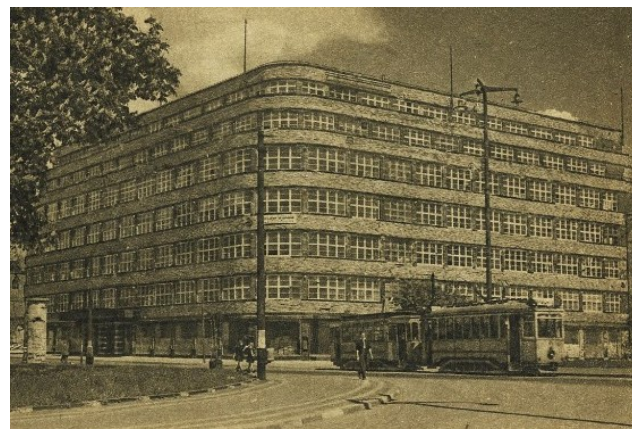

b)

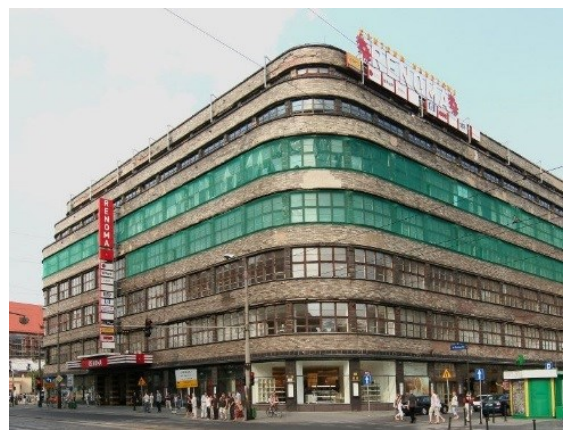

Fig. 2. a) The building of pre-war "Renoma" department store in 1948. [source: Public domain: https://polska-org.pl/973435, foto.html?idEntity $=508876]$, b) Department store before reconstruction in 2006 [source: Public domain: https://polska-org.pl/880447,foto.html?idEntity=508876].

The first floor was put into operation in 1953. The second one was being prepared for use for an approximately 15 years. The fifth and sixth floors came into operation in 1984-1985. In 1977, the building was enlisted into the cultural heritage register as a flagship artwork of European modernism. At the end of the 1990s, the building was privatised. In 2005-2009, the reconstruction of the building and expansion works were carried out - Fig. 2b, Fig. 3.

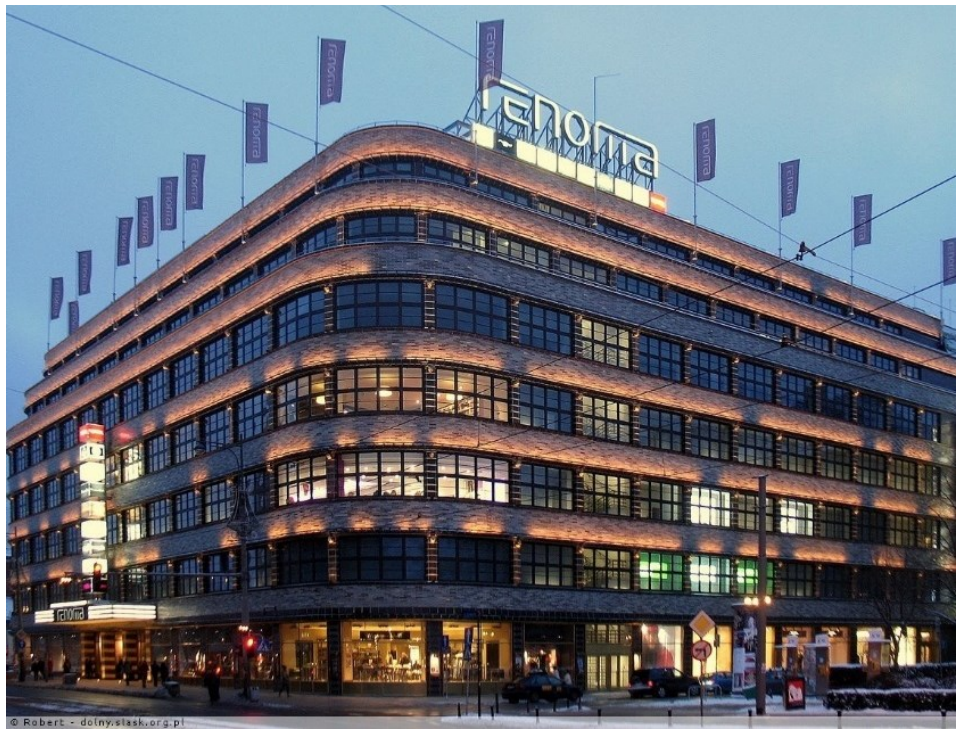

Fig. 3. Renoma" department store after reconstruction in 2010 [source: Public domain: https://polskaorg.pl/3257754,foto.html?idEntity=508876].

Demolition and deconstruction works carried out in connection with the reconstruction of the building enabled comprehensive diagnostics of the technical condition of the loadbearing structure of this building [1-3], including existing inter-storey slabs. During these works, many inspection holes were made "in situ", taking into account the damages and failures of these ceilings caused by warfare and extensive fire. However, it should be emphasized that these activities significantly weakened this structure. Hence at work [4], the stability of the building was also analysed. The system of additional construction elements (braces) and individual solutions, such as timber beams as well as portal transfer frames, were used in places where structural columns were removed. Attention was also paid to the 
reinforcement of masonry walls and foundations, taking into account the historic character of the analysed building [5,6].

This paper presents the results of analysis of the technical condition and load-bearing capacity of these ceilings on four levels ranging from -1 to 2 , which were reinforced with an additional concrete ceiling slab poured on trapezoidal sheet in the post-war period. The aim of the diagnostic works was to determine the possibility of leaving pre-war brick slabs of Klein type with Förster type hollow bricks in the structure of these intermediate floors.

\section{Assessment of the technical condition of the brick and concrete ceiling slabs}

The existing brick slab of the inter-storey Klein-type ceilings with Förster's hollow bricks was reinforced with round, smooth bars with diameters of 6,8 and $10 \mathrm{~mm}$ every second hollow brick. It should be noted that a significant lack of mortar adhesion to reinforcing steel was diagnosed in the ceramic blocks. The most probable cause of this occurrence was the wartime fire. The mortar strength class was determined as M7 according to PN-90/B-14501 Polish construction standard and by means of forging and scratching tests.

a)

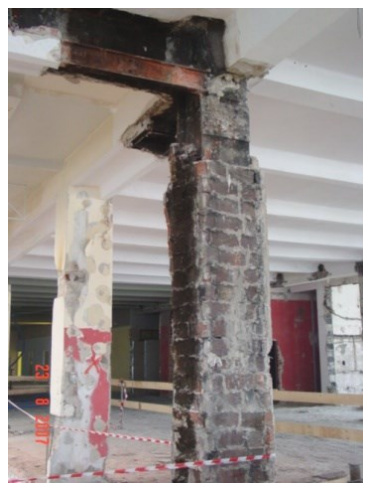

d)

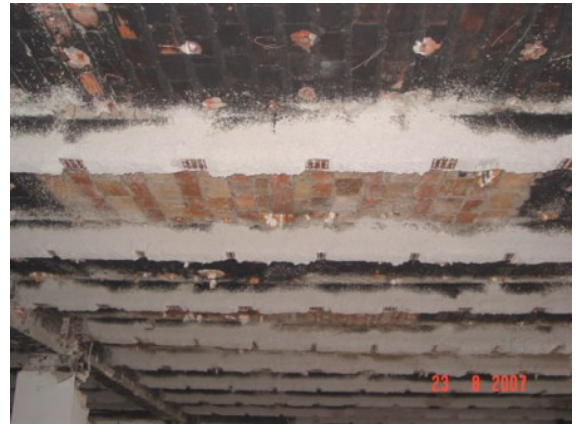

b)

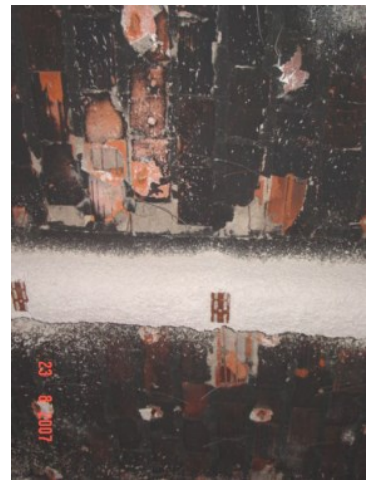

c)

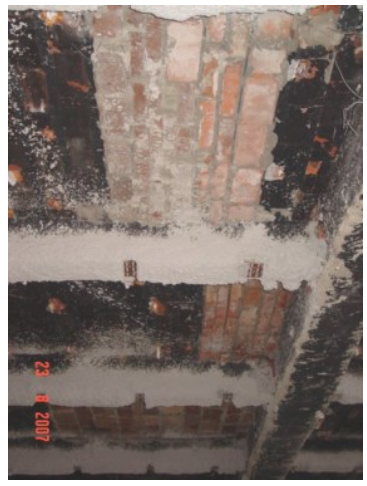

e)

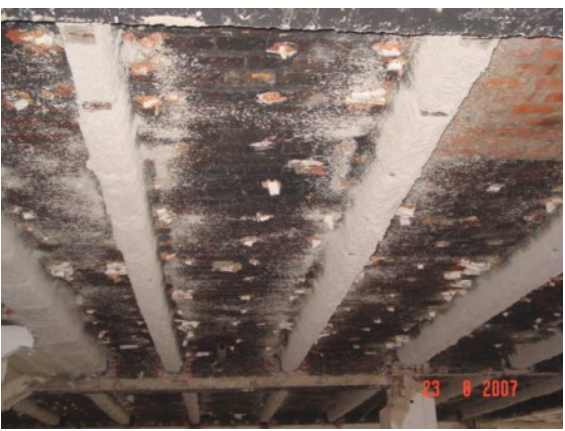

Fig. 4. a) $\div$ e). Technical condition of Förster type ceramic blocks based on steel ceiling beams. Visible smoke covered surfaces of ceramic ceilings and column damage.

The following typical damages to the filling of the ceilings - ceramic hollow bricks have been found:

a) $1^{\text {st }}$ level (evaluation from the bottom of the ceiling) - about $25 \%$ of Förster type hollow bricks suffered damage of various sizes in their bottom parts. Some of the holes in the hollow bricks have been filled with polyurethane foam or insulation. The smoke covered bricks were observed -Fig. 4. The ceramic floor slab above the ground floor level showed the highest number of hollow brick damages among the assessed ceilings. A random lack of mortar in the joints between the blocks was 
observed. The stratification of the ceiling layers was not visible. However, when tapping randomly selected unbroken blocks, some of the hollow bricks made a hollow sound, which indicated internal cracks;

b) $2^{\text {nd }}$ level - significant smoke covered bottom surfaces of the hollow bricks as well as local damage of the slab was observed.

Due to these fire damages, the inter-story floors have been strengthened by the use of an additional floor layer of the concrete slab on a T55 / 188 trapezoidal sheet. In this way, the Förster ceramic blocks were partially de-stressed. As a result of the inspection holes made in-situ, it was established that the sheet together with the concrete slab lied directly on the levelling layer of the ceramic plate.

\section{Assessment of the technical condition of the concrete ceiling slab}

The concrete slab was made on a T88 / 188 trapezoidal sheet, $0.88 \mathrm{~cm}$ thick. When carrying out inspection holes pits (e.g. in the ceiling at the "2" level), some areas where the sheet was incorrectly arranged were found - folds parallel to the steel floor beams - Fig. 5.

a)

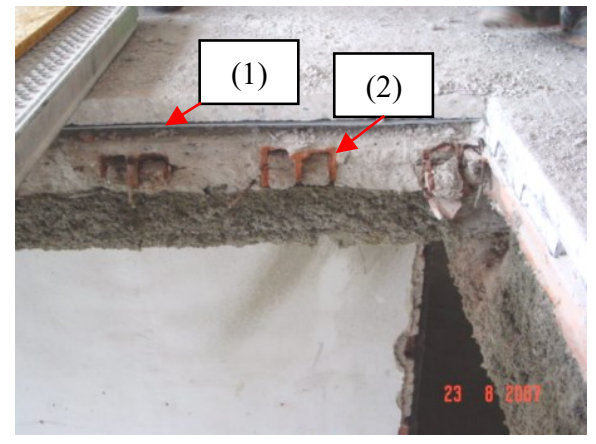

b)

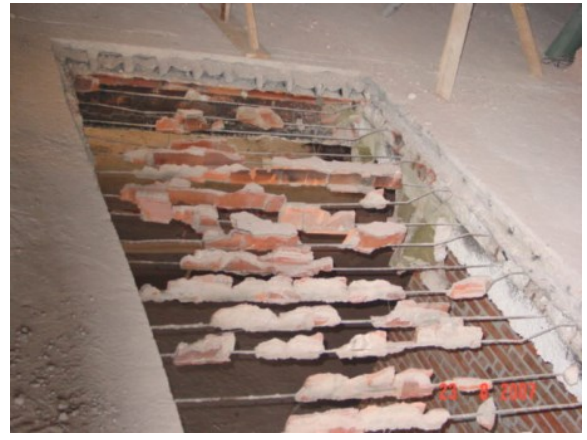

Fig. 5. Examples of a parallel arrangement of trapezoidal sheets (1) to steel ceiling beams (2). There are visible There are visible reinforcing steel bars of the ceramic plate reinforcing steel bars of the ceramic plate - see Fig. b).

Moreover, in the inspection holes made, a large dispersion in the measured thicknesses of the concrete slab over the trapezoidal sheet was found - from $3 \mathrm{~cm}$ to $9 \mathrm{~cm}$. The average thickness of the concrete slab was estimated at about $5 \mathrm{~cm}$. The top surface of the slab was not leveled and showed significant irregularities - Fig. 6. At about $10 \%$ of the surface, the top surface of the concrete slab was spalling, exposing the reinforcing bars around the entire circumference - Fig. 7.

The measurements and tests using Proceq Profoscope 4 were carried out. The Profoscope uses electromagnetic pulse induction technology to detect rebars. Its advanced signal processing allows the localization of a rebar, the determination of the cover and the estimation of the bar diameter. As a result of the measurements, it was found that the concrete cover thickness is less than $10 \mathrm{~mm}$ on approximately $25 \%$ of the floor area (on randomly distributed surfaces).

Furthermore, on the basis of measurements of concrete compressive strength using a Schmidt hammer (using the scaling curve from expertise No. 080024/2005 from Poltebub and its own hypothetical regression curve), it was determined that the concrete strength class in the reinforced slab is not lower than $\mathrm{C} 16 / 20$. The measuring points were selected only above the ribs. 
a)

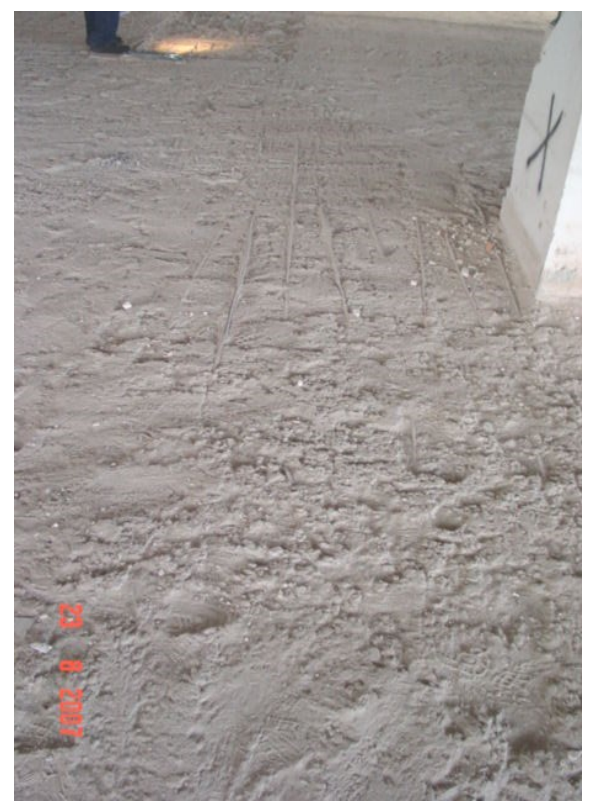

b)

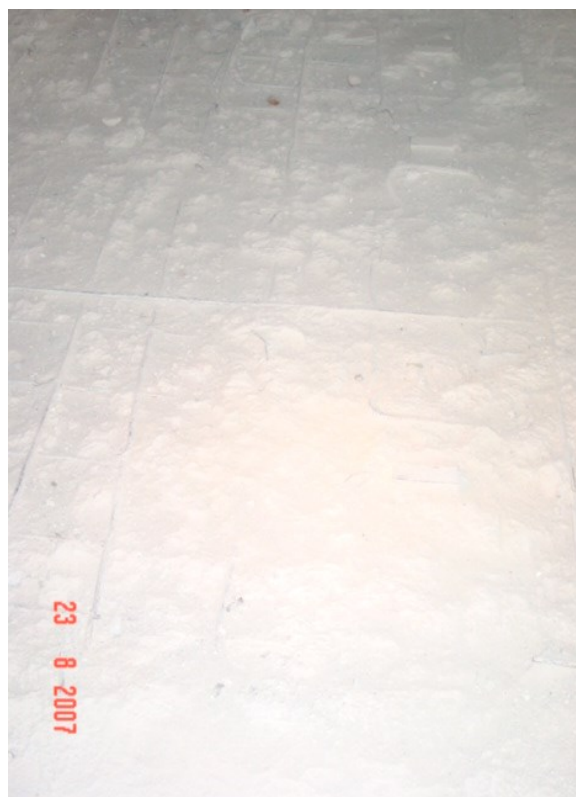

Fig. 6. Technical condition of the top layer of the concrete slab on the trapezoidal sheet.

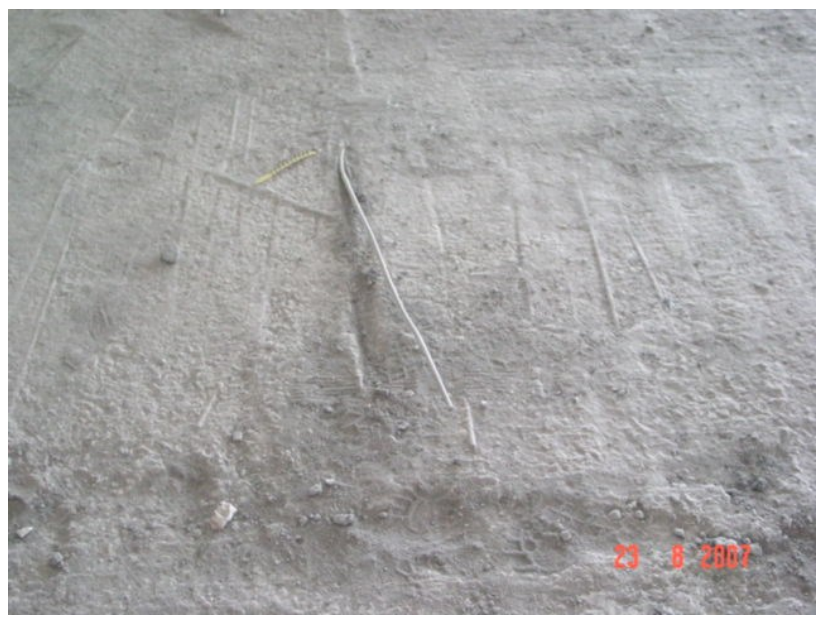

Fig. 7. Technical condition of the reinforcement of the upper concrete slab.

Joints connecting the concrete floor slab with steel ceiling beams were made in various ways (Fig. 8):

- on the $2^{\text {nd }}$ level: as vertical, vertically welded sections of a T-65 profile (a), with a length of $80 \mathrm{~mm}$ and a spacing of $25 \mathrm{~cm}$,

- on the $1^{\text {st }}$ level: as sections of the L40 x $40 \times 8$ profile, welded horizontally with one edge, at a spacing of about $1.0 \mathrm{~m}$ or vertical bars $\varnothing 10$ from steel 34 GS welded to the reinforcement;

- on ground level: as vertically welded sections of T-50 profile, with a length of $50 \mathrm{~mm}$ and a spacing of $50 \mathrm{~cm}$. 


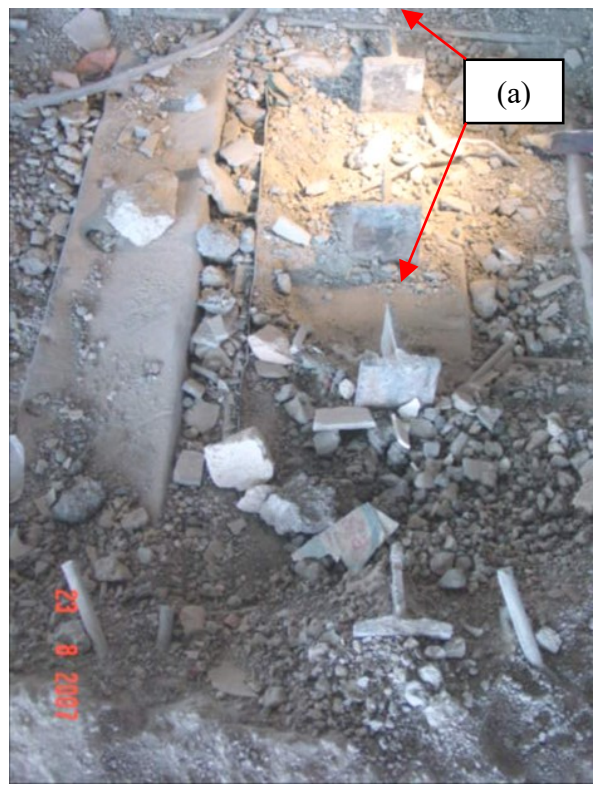

Fig. 8. Welded concrete slab joints and steel ceiling beams.

The location of the joining connectors using Profoscope was not possible due to the presence of surface reinforcement of this panel. Their inventory would require removing the entire surface layer of concrete above the joists. It should be noted that due to the presence of joining connectors, the trapezoidal sheet had not been placed on the joists.

The testing on the properties of joints (abovementioned connectors) was carried out by the Welding Institute in Gliwice [2]. It showed that "due to the heat affected steel zone from 1929 (steel floor beams), the connectors do not meet the requirements as for a JRG1 steel quality group according to PN-EN 10025-2: 2002 "this steel should not be combined using welding with other steels". This means that the existing and applied welded joints connecting the concrete slab with the steel ceiling beams had a reduced load-bearing capacity for shearing.

\section{Determination of the Ultimate Limit State of the concrete floor slab on trapezoidal sheet}

In the inter-storey ceilings, there were ceramic Klein type slabs (Förster block), which carried only their own weight were situated. These slabs, due to their long service life and due to war damage, were found in a very bad technical condition. Hence, the subject of further standard verification calculations and analysis was a monolithic concrete floor slab with ribs laid on T55/188 trapezoidal sheet and a thickness of $0.88 \mathrm{~cm}$ (Fig. 9). It was the basic structural element of the floor layers of the building.

It should be noted that the designer of the reconstruction modernization of the building assumed that the ribs of this slab are perpendicular to the steel ceiling binding joist. 
On the basis of the cross-sectional geometry of this floor slab, the following symbols were adopted for further analysis for the preliminary estimation of the cross-section bearing capacity:

- $\quad h_{p}$-the assumed thickness of the concrete slab above the profile of the trapezoidal sheet: $6.0 \mathrm{~cm}$ (when carrying out the local inspections the various values of the slab thickness were measured, reaching in some measuring points up to $3 \mathrm{~cm}$ ),

- $\quad b_{d}$ - the slab section width used for calculations: $18.8 \mathrm{~cm}-$ see Fig. 9 ,

- $\quad h_{\min }$ - the distance of the centre of gravity of the trapezoidal sheet from the upper compressed fibres of the concrete slab: $7.95 \mathrm{~cm}$,

- $h_{\text {dod }}$ - the height of the trapezoidal sheet: $5.5 \mathrm{~cm}$,

- $A_{s 11}$ - the area of the top surface of the trapezoidal metal sheet: $1.06 \mathrm{~cm}^{2}$,

- $A_{s 22}$ - the area of the web of the trapezoidal metal sheet: $1.03 \mathrm{~cm}^{2}$,

- $A_{s 33}$ - the area of the bottom surface of the trapezoidal metal sheet: $0.37 \mathrm{~cm}^{2}$,

- $\quad x-$ the height of the compression zone of the concrete slab.

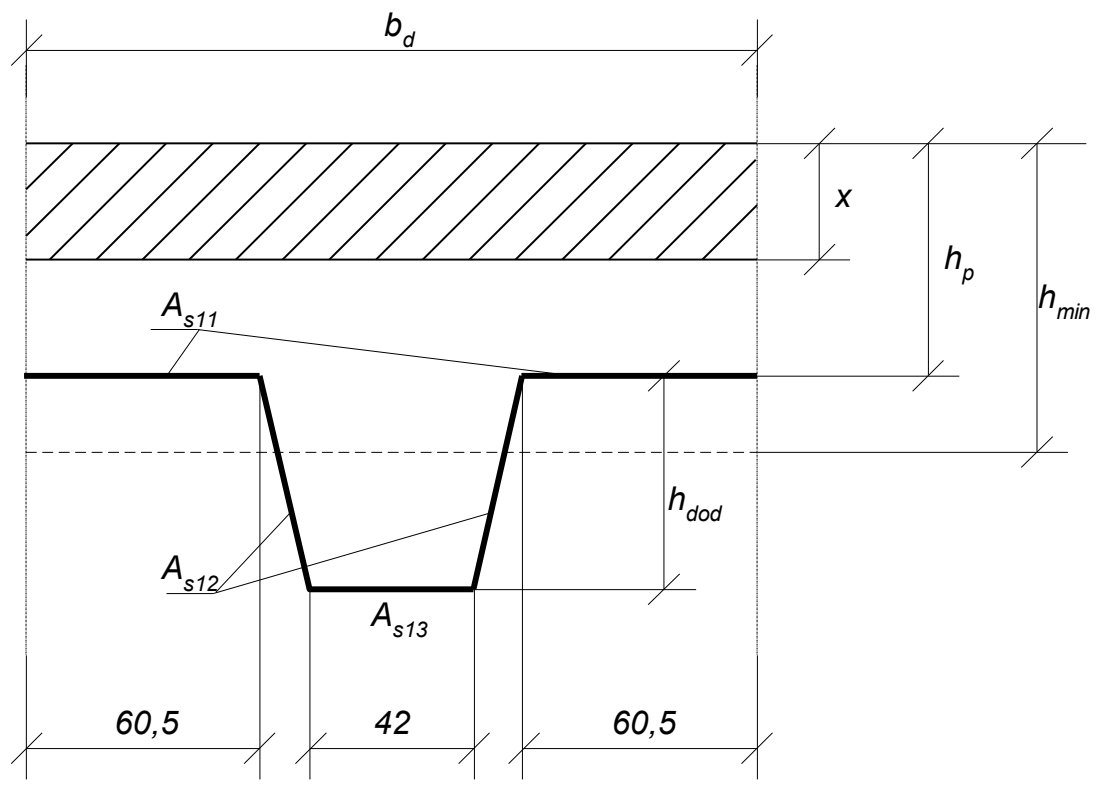

Fig. 9. The geometry of the concrete floor slab with ribs, made on a trapezoidal sheet.

Dimensions in $\mathrm{mm}$.

B20 $(\mathrm{C} 16 / 20)$ concrete class with the compressive strength $f_{c d}=10.6 \mathrm{MPa}$ and the modulus of elasticity $E_{c m}=27.5 \mathrm{GPa}$ were adopted for static and strength analysis, without taking into account rheological effects. Moreover, the A-I steel class for trapezoidal sheet, with the tensile strength $f_{y d}=210 \mathrm{MPa}$ and the modulus of elasticity $E_{s}=200 \mathrm{GPa}$, was applied for calculations. The determined ratio of the steel modulus of elasticity and concrete modulus of elasticity is:

$$
n=\frac{E_{s}}{E_{c m}}=7,273
$$


The height of the compression zone of concrete slab $x$ was calculated from the equation:

$$
b_{d} \cdot x \cdot \frac{x}{2}=n \cdot\left(A_{s 11}+A_{s 12}+A_{s 13}\right) \cdot\left(h_{\min }-x\right)
$$

Assuming that $A_{s 1}=A_{s 11}+A_{s 12}+A_{s 13}$, the equation was transformed into a second-order polynomial:

$$
\frac{b_{d}}{2} x^{2}+n A_{s 1} x-n A_{s 1} h_{\min }=0
$$

The following results were obtained:

$$
\begin{aligned}
& \Delta=\left(n A_{s 1}\right)^{2}+4 \frac{b_{d}}{2} n A_{s 1} h_{\min } \\
& x=\frac{-n A_{s 1}+\sqrt{\Delta}}{2 \frac{b_{d}}{2}}=3,055 \mathrm{~cm}
\end{aligned}
$$

The values of stresses in the steel sheet were determined in accordance with the scheme shown in Fig. 10 continue preliminary estimation of the cross-section bearing capacity.

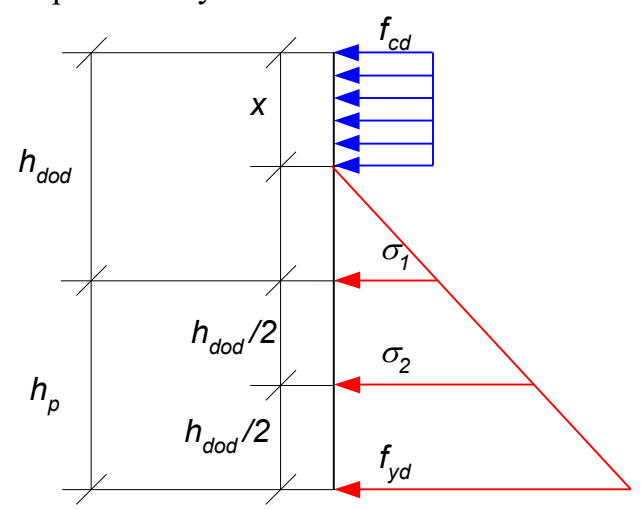

Fig. 10. Distribution of stresses in the cross-section of the concrete floor slab made on the trapezoidal sheet.

The obtained stress values were:

$$
\begin{gathered}
\sigma_{1}=\frac{\left(h_{p}-x\right) f_{y d}}{h_{p}-x+h_{d o d}}=73.24 \mathrm{MPa} \\
\sigma_{2}=\frac{\left(h_{p}-x+\frac{h_{d o d}}{2}\right) f_{d}}{h_{p}-x+h_{d o d}}=141.62 \mathrm{MPa}
\end{gathered}
$$


The lever arm distances of the internal forces for the individual sheet elements were determined according to the formulas:

$$
z_{1}=h_{p}-\frac{x}{2}, \quad z_{2}=h_{p}+\frac{h_{d o d}}{2}-\frac{x}{2}, \quad z_{3}=h_{p}+h_{d o d}-\frac{x}{2}
$$

The load-bearing capacity of the concrete floor slab with the ribs made on the trapezoidal sheet was:

$$
M_{p}^{\max }=\sigma_{1} z_{1} A_{s 11}+\sigma_{2} z_{2} A_{s 12}+f_{d} z_{3} A_{s 13}=2.18 \mathrm{kNm}
$$

Table 1 presents the results of the numerical analysis, including the value of $x$ - the height of the compression zone of the concrete slab, obtained stress values in the metal sheet $\sigma_{l}$ and $\sigma_{2}$ and load-bearing moment of the analysed cross-section $M_{p}^{\max }$, depending on the slab thickness $h_{p}$.

\begin{tabular}{|c|c|c|c|c|}
\hline $\begin{array}{c}\begin{array}{c}\text { Slab } \\
\text { thickness }\end{array} \\
\boldsymbol{h}_{\boldsymbol{p}} \\
{[\mathrm{cm}]}\end{array}$ & $\begin{array}{c}\text { Height of the } \\
\text { compression } \\
\text { zone of the } \\
\text { concrete slab } \\
\boldsymbol{x} \\
{[\mathrm{cm}]}\end{array}$ & $\begin{array}{c}\text { Determined } \\
\text { stress value } \\
\sigma_{I} \\
{[M P a]}\end{array}$ & $\begin{array}{c}\text { Determined } \\
\text { stress value } \\
\boldsymbol{\sigma}_{2} \\
{[M P a]}\end{array}$ & $\begin{array}{c}\text { Load-bearing moment } \\
\text { of the analysed cross- } \\
\text { section } \\
\boldsymbol{M}_{\boldsymbol{p}}^{\max } \\
{[\mathrm{kNm}]}\end{array}$ \\
\hline 6.0 & 3.06 & 73.21 & 141.62 & 2.18 \\
\hline 5.0 & 2.81 & 59.81 & 134.91 & 1.82 \\
\hline 4.0 & 2.55 & 43.88 & 126.94 & 1.48 \\
\hline 3.0 & 2.26 & 24.81 & 117.40 & 1.18 \\
\hline
\end{tabular}

Table 1. Results of the numerical analysis for different values of slab thickness $h_{p}$.

According to the recommendations of the designer of the reconstruction and modernization of this historic building, the maximum operational load of the existing interstory floors should be determined from the formula:

$$
q_{u}=\frac{8 M_{p}^{\max }}{l_{t}^{2} b_{d}}
$$

The operational pressure values of the concrete slab on the trapezoidal sheet, depending on the thickness of the slab and determined on the basis of the above assumptions, are presented in Table 2. The bold type indicates the cases of reduced thickness of the concrete floor slab $h_{p}$ for which the Ultimate Limit State is not being met. 
Table 2. The operational load value of the concrete slab, depending on the thickness of the slab $h_{p}$

\begin{tabular}{|c|c|}
\hline $\begin{array}{c}\text { Slab } \\
\text { thickness } \\
\boldsymbol{h}_{\boldsymbol{p}} \\
{[\mathrm{cm}]}\end{array}$ & $\begin{array}{c}\text { Operational } \\
\text { pressure for } \\
\text { the slab } \\
\boldsymbol{q}_{\boldsymbol{u}} \\
{\left[\mathrm{kN} / \mathrm{m}^{2}\right]}\end{array}$ \\
\hline 6.0 & 5.25 \\
\hline 5.0 & $\mathbf{4 . 3 8}$ \\
\hline 4.0 & $\mathbf{3 . 5 8}$ \\
\hline 3.0 & $\mathbf{2 . 8 5}$ \\
\hline
\end{tabular}

\section{The Serviceability Limit State of the concrete floor slab on trapezoidal sheet - limit state of deflection}

The moment of inertia of the analysed cross-section of the concrete slab on the trapezoidal sheet was determined from the formula:

$$
I_{s}=\frac{b_{d} x^{3}}{3}+n A_{s 1}\left(h_{\min }-x\right)^{2}
$$

In the next step, the maximum deflection value was determined for the concrete slab with the span of the section $2.1 \mathrm{~m}$ and designed as simply supported. An imposed operational load of $5 \mathrm{kN} / \mathrm{m}^{2}$ is used together with a total permanent load (the deadweight of the concrete slab section). The maximum deflection was calculated from the following formula, without taking into account rheological effects:

$$
f=\frac{5 q l^{4}}{384 E_{c m} I_{s}}
$$

The results of performed Serviceability Limit State calculations for $2.1 \mathrm{~m}$ span of the slab section and the various thicknesses of the slab $h_{p}$ are shown in Table 3. It should be noted that the permissible value of deflection, determined from the formula (12), is:

$$
f_{\max }=\frac{l}{200}=10,5 \mathrm{~mm}
$$

Table 3. Results of performed Serviceability Limit State calculations for $2.1 \mathrm{~m}$ span of the slab section and the various thicknesses of the slab $h_{p}$

\begin{tabular}{|c|c|c|c|}
\hline $\begin{array}{c}\text { Slab } \\
\text { thickness } \\
\boldsymbol{h}_{\boldsymbol{p}} \\
{[\mathrm{cm}]}\end{array}$ & $\begin{array}{c}\text { Moment of inertia } \\
\text { of the cross-section } \\
\boldsymbol{I}_{\boldsymbol{s}} \\
{\left[\mathrm{cm}^{4}\right]}\end{array}$ & $\begin{array}{c}\text { Deadweight of the } \\
\text { concrete slab section } \\
\boldsymbol{g}_{\boldsymbol{c}} \\
{[\mathrm{kN} / \mathrm{m}]}\end{array}$ & $\begin{array}{c}\text { The } \\
\text { maximum } \\
\text { deflection } \\
\boldsymbol{f} \\
{[\mathrm{mm}]}\end{array}$ \\
\hline 6.0 & 608.06 & 0.376 & 1.99 \\
\hline 5.0 & 446.19 & 0.330 & 2.62 \\
\hline 4.0 & 311.06 & 0.280 & 3.62 \\
\hline 3.0 & 202.01 & 0.241 & 5.35 \\
\hline
\end{tabular}


Additionally, the maximum deflection values were determined in accordance with the recommendations of the designer, assuming the design value of the slab span of $4.2 \mathrm{~m}$ and a five-span continuous beam model. The values of the deflection calculated on the basis on the abovementioned design assumptions and depending on the thickness of the concrete slab $h_{p}$ are presented in Table 4. In this case, the permissible value of the deflection, determined using the formula (13), is $21.0 \mathrm{~mm}$. The bold type in Table 4 indicates the cases of reduced thickness of the concrete slab $h_{p}$ for which the Serviceability Limit State (the limit state of deflection) was not met.

Table 4. Results of performed Serviceability Limit State calculations for the recommended value of the slab span section $(4.1 \mathrm{~m})$ and the various thicknesses of the slab $h_{p}$.

\begin{tabular}{|c|c|}
\hline $\begin{array}{c}\text { Slab } \\
\text { thickness } \\
\boldsymbol{h}_{\boldsymbol{p}} \\
{[\mathrm{cm}]}\end{array}$ & $\begin{array}{c}\text { The maximum deflection } \\
\boldsymbol{f} \\
{[\mathrm{mm}]}\end{array}$ \\
\hline 6.0 & $21.3 \cong f_{\max }=21.0$ \\
\hline 5.0 & $\mathbf{2 7 . 9}$ \\
\hline 4.0 & $\mathbf{3 8 . 6}$ \\
\hline 3.0 & $\mathbf{5 7 . 1}$ \\
\hline
\end{tabular}

\section{Discussion}

On the basis of the static and strength analysis, it was found that only at the thickness of the concrete floor slab at $6 \mathrm{~cm}$, the Ultimate Limit State (ULS) and Serviceability Limit State (SLS) conditions were met at the operational load of $5 \mathrm{kN} / \mathrm{m}^{2}$ (see Table 2 and Table 4). Due to the fact that during the local inspection, the values of the concrete slab thickness lesser than $6 \mathrm{~cm}$ were found, it was necessary to make an inventory of the slab thickness on the whole surface of the inter-story floors. This is particularly important because, apart from this issue, it was found that some cases of the ribs of this plate were made perpendicular to the binding joists of the existing ceramic ceiling - see Fig. 2. Such a calculation model and design solutions were not considered by the designer of the reconstruction and the modernization of "Renoma" Department Store building in Wroclaw.

In the case of this type of structural layering system (application of the trapezoidal metal sheet) when analysing the ULS and the SLS conditions, it was necessary to take into account the rectangular-shape profile of the concrete floor slab section, which means without ribs. This cross-section should also correspond to the height (thickness of the $h_{p}$ ) of the slab laid on the trapezoidal sheet profile. The parameters of such a single continuous section of the slab with the width of $b_{d}=18.8 \mathrm{~cm}$ and the area of the top surface of the trapezoidal sheet of $A_{s 11}=1.65 \mathrm{~cm}^{2}$ are shown in Table 5 . 
Table 5. Results of the numerical analysis of the rectangular-shape profile of the concrete floor slab section for different values of slab thicknesses $h_{p}$.

\begin{tabular}{|c|c|c|}
\hline $\begin{array}{c}\text { Slab thickness } \\
\boldsymbol{h}_{\boldsymbol{p}} \\
{[\mathrm{cm}]}\end{array}$ & $\begin{array}{c}\text { Height of the compression } \\
\text { zone of the concrete slab } \\
\boldsymbol{x} \\
{[\mathrm{cm}]}\end{array}$ & $\begin{array}{c}\text { Load-bearing moment of the } \\
\text { analysed cross-section } \\
\boldsymbol{M}_{\max } \\
{[\mathrm{kNm}]}\end{array}$ \\
\hline 6.0 & 2.20 & 1.70 \\
\hline 5.0 & 1.97 & 1.40 \\
\hline 4.0 & 1.71 & 1.09 \\
\hline 3.0 & 1.42 & 0.80 \\
\hline
\end{tabular}

For verification of the ULS and the SLS conditions, a simply supported beam scheme was assumed because the trapezoidal sheet was not placed on the floor beams due to the presence of joining connectors. Thus, the concrete slab carried only the load with its own weight, but due to the phenomenon of redistribution of internal forces (and stresses), the slab worked mainly along the ribs of the trapezoidal sheet on the span between the $7.7 \mathrm{~m}$ beams. Table 6 presents the results of plate deflection at the maximum spacing of steel ceiling beams $2.5 \mathrm{~m}$ for the various slab thicknesses $h_{p}$. The permissible value of this deflection was determined using the formula (13):

$$
f_{\max }=\frac{l}{200}=\frac{2.5}{200}=12.5 \mathrm{~mm}
$$

Table 6. Results of performed Serviceability Limit State calculations of the slab deflection at the maximum spacing of steel ceiling beams $2.5 \mathrm{~m}$ for the various slab thicknesses $h_{p}$.

\begin{tabular}{|c|c|}
\hline $\begin{array}{c}\text { Slab } \\
\text { thickness } \\
\boldsymbol{h}_{\boldsymbol{p}} \\
{[\mathrm{cm}]}\end{array}$ & $\begin{array}{c}\text { The maximum deflection } \\
\boldsymbol{f} \\
{[\mathrm{mm}]}\end{array}$ \\
\hline 6.0 & 6.72 \\
\hline 5.0 & 8.93 \\
\hline 4.0 & $\mathbf{1 5 . 8 7}$ \\
\hline 3.0 & $\mathbf{3 0 . 0 3}$ \\
\hline
\end{tabular}

The bold type in Table 6 indicates the cases for which the Serviceability Limit State (limit state of deflection) was not met.

The reduced thickness $h_{p}$ of the concrete floor slab laid on a trapezoidal sheet below the assumed $6 \mathrm{~cm}$ caused exceeding the SLS (the Serviceability Limit State) of this basic loadbearing element of inter-story floors at many measuring points. Particularly, the fields where profiles of these sheets are parallel to steel ceiling beams (perpendicular to steel binding joists) could be observed. This unfavourable static scheme, which was not considered by the designer of the reconstruction and modernization of the department store, is documented in the results of the inspection holes made in many check points - see Fig. 4. 
It should be emphasized that in accordance with the Article 5(1) of the Polish Act Construction Law, "a building together with associated installation should have been designed and constructed in the manner specified in the technical regulations, including technical and construction knowledge." In addition, according to above mentioned regulations, it was necessary to additionally ensure that fulfilment of the basic requirements concerning, among others, the safety of the building. This means that during conducting the safety analysis and calculations of the load-bearing structure of the inter-floor ceilings of the building, it was necessary to possess full knowledge about the built-in construction materials, the applied construction technology and solutions as well as the geometry of the element's profiles in the entire structure. In addition, in order to ensure the safe operation of damaged brick floor slabs (ceilings), it was necessary to strengthen their bottom surfaces - Förster brick blocks, e.g. by using expanded metal mesh with sprayed plaster.

\section{Conclusions}

To sum up, due to the unfavourable structural design and applied solutions of the concrete floor slab made on the trapezoidal metal sheet, it was not possible to ensure the safety of all elements of the load-bearing structure (the ULS and the SLS). In addition, the existing welded joints connecting the concrete slab with steel joists had a reduced shear capacity. Leaving masonry elements of Klein type ceiling (Förster's block) in the arrangement of these ceramic ceilings, which were also in a very bad technical condition, did not allow to guarantee a minimum period of warranty for defects in renovated and reconstructed ceilings of this historic building. Therefore, in order to fully ensure the safety requirements for the load-bearing structure, it was recommended to replace the existing inter-floor ceiling structure with monolithic reinforced concrete slabs with the simultaneous demolition of Förster type ceramic blocks. Such a structural design solution required the development of a construction executive design. These additional construction works slightly increased the total costs of the reconstructed and modernized structure, but allowed, however, a long period of warranty for the defects of the modernized inter-story floors.

Acknowledgment for the WARBUD company for making both the construction site and documentation available for research and analysis

\section{References}

1. Report: J. Gierczyk, Technical expertise regarding material testing of structural elements of the Department Store of "Renoma" Center in Wroclaw at Podwale Street (Wrocław, 2005) [in Polish]

2. Report: M. Zeman, Research work No. B-162/07: "Study of the properties of welded joints made of $18 G 2$ steel and cut from the old steel structure of Renoma Department Store in Wroctaw" (Instytut Spawalnictwa, Gliwice, 2007) [in Polish]

3. Jopint publication: Certified judgment and opinion No $\mathrm{zb} / 44 / 2007$ on "Impact and chemical composition testing of samplings taken from "Renoma" steel structure in Wrocław" (Instytut Spawalnictwa, Gliwice, 2007) [in Polish]

4. J. Dudkiewicz, P. Organek, Materiały Budowlane, 11, pp. 125-128 (2015) [in Polish]

5. R. Chmielewski, MATEC Web of Conf., 174, 03010 (2018)

6. R. Chmielewski, P. Muzolf, MATEC Web of Conf. 174, 03012 (2018) 